\section{Dimensions of Including Emotional Intelligence in the Educational Curriculum for Higher Education Level}

\author{
Cristian RISTEA 1 , \\ Cristiana PORFIREANU ${ }^{2}$, \\ Nicoleta LEONTE ${ }^{3}$
}

${ }^{1}$ Assist., Ph.D., University Spiru Haret, Physical Education and Sport Faculty, Bucharest, Romania, cristiristea163@gmail.com,+40723573146.

${ }^{2}$ Lecturer, Ph.D., A, Academy of Economic Studies, Bucharest, Romania, criss.porfi@gmail.com, +40723306709.

${ }^{3}$ Lecturer, Ph.D., University "Politehnica" of Bucharest, Romania, nicoleta_leonte@yahoo.com, +40721879416.
Abstract: A large number of teachers and researchers admit that at the end of their studies, young people are not prepared for future challenges, both as individuals and as members of society.

The cognitive perspective of curricular and didactic approaches is not enough to be successful and happy. Practical skills are required to manage emotions, not only to "nourish" the mind. From the perspective of new theories about the nature of emotions, if the emotional intelligence of young people is developed through social and emotional learning, it represents an enormous luggage for their personal and professional future.

Studies show that Emotional Intelligence (EI) is the best predictor for future acquisitions, for success, compared to the traditional intelligence (cognitive). It is a transferable ability that allows rapid adaptation to contemporary social changes.

In this context, the first step is to understand the extraordinary role of using emotions intelligently. Success in life depends on the emotional and social skills which are formed throughout formal education or, at least, which should be pursued as objectives, beyond disciplines.

Keywords: emotional intelligence; curriculum; higher education.

How to cite: Ristea, C., Porfireanu, C., \& Leonte, N. (2018). Dimensions of Including Emotional Intelligence in the Educational Curriculum for Higher Education Level. Moldavian Journal for Education and Social Psychology, 2(1), 17-24. https://doi.org/10.18662/mjesp/02 


\section{Introduction}

In the past years, in countries such as U.S.A, Great Britain, France and Germany were introduced educational programs for the development of emotional intelligence that really showed efficient results. The purpose of these programs were: discipline;

- Creating responsible adults that are capable of embracing a positive

- Creating a secured climate based on the self-confidence and trusting the others;

- Promoting assertive communication and the negotiation of conflicts;

- Developing a sense of balance as an important source for reducing stress, anxiety and negative feelings;

- Practicing the ability of becoming aware of feelings, understanding and having gratitude for other's emotions;

- Showing a flexible, generous and emphatic attitude;

- Good management of time resources;

The view of the emotional competence development assumes that young people can improve the well-being by taking decisions and managing problems in a responsible way by facing efficiently daily paper problems and stressful events in life (Durlak \& Wells, 1997).

\section{Theoretical Background}

Trough functioning the concept of emotional intelligence, there has been a series of investigations of books and studies published in interdisciplinary areas (sports, psychology, sociology, pedagogy), between 20002017.

The investigative approach was created consulting the articles of the next data bases: ScienceDirect, Ebsco, Elsevier and Springerlink.

D. Goleman (2008) suggestively explains in his book „Emotional Intelligence" the phrase: the neurobiology of virtuosity. The author says that „sportsman that overvalue themselves in competitions experience a higher positive mood reached only when their great results seem to be effortless and the audience plus the other competitors are vanished for a moment". The author calls such mood "trance” and the capability of reaching such condition defines actually a moment of maximum emotional intelligence. Moreover, the "trance" represents an absolute emotion that helps the performance and the accumulation of knowledges. The sportsman that lives such condition manages and focuses his emotions and also concentrates himself on the mission that needs to be done. 
Studies made by J. Ciarrochi, A.Y.C. Chan, J. Bajgar (2000) describe a critical evaluation of emotional intelligence. The assessment was made through a MEIS test (Multi-Factor Emotional Intelligence Scale) and it was given to a group of Australian students along with personality and IQ tests. The subjects have been induced with various emotional conditions that were then examined with the help of an MEIS test, along with IQ and personality evaluations. It has been noticed that emotional intelligence was not related with the IQ, but still there was a connection with some structures of the personality (such as empathy), and also with other criteria (life satisfaction).

Barchard K. (2003) asked himself if emotional intelligence helps predicting the academic success. In this study, the capacity of emotional intelligence to anticipate the academic results was tested through a cross section of students, using final years qualifications. The predictive validity of emotional intelligence was compared with the predictive validity of cognitive traditional abilities and the five big dimensions of the personality (Big Five). After the study was made, it has been observed that only some factors of emotional intelligence predicted the academic success and none of these factors have demonstrated the predictive validity for the academic success.

Lane A., Thelwell R., Devanport T. J. (2009) present in a full study the current relation between emotional intelligence and mood associated with sportive and academic performances. The subjects answered the EIS tests (Emotional Intelligence Scale), and the answers were related with the mood of the subjects (Brunel Scale). The analysis of the results indicated a positive relation between the state of mind and the sportive performances, being way stronger for the sportive areas: athletics, basketball, football. An additional analysis explored the role of emotional intelligence in the relation spiritual condition- sportive performances. The Mancova test (comparing differences between environments) indicated the association of emotional intelligence with the spiritual condition in different situations.

In Romania, the profile literature is not that prepared to approach the emotional intelligence. Among the Romanian authors that wrote about emotional intelligence, in articles or books, stands: Neacsu I., Roco Mihaela., Chelcea S., Fodor D., Marcu V.

Neacsu I. (2010) thinks that using emotional intelligence follows that objectives that only aims the academic success, especially social and professional reputation. In the sports domain, it is useful to endow the sportsman with capacities of building relations and use them productively, to work on a team, to cooperate and to give an ideal value to their own emotions.

M. Roco (2004) presents the results of some studies about the level of emotional intelligence at different categories of subjects and also the constant 
relations between emotional intelligence and other dimensions of the personality. The subjects made it through the Emotional Intelligence Test (the adults version). The results indicated a medium value of the emotional coefficient, calculated in percentages being 35,7\% (the maximum was 100). The girls obtained a higher value, $39,7 \%$ than boys $22,9 \%$, which matches with the statistics offered by the profile literature.

We are observing that in the general psychology and sportive area, there is a higher interest in approaching emotional intelligence in the context of creating the young people personalities.

\section{Argument of the paper}

Having in consideration the focus of the educational system on the student, through this work we want to bring out the existing programs that can improve the developing of emotional intelligence at young people with the purpose of achieving future professional performances and a higher quality of life.

With the educational reform of the academy, the curriculum of sports must establish new relations between knowledge, valuation and action.

\section{Programs for developing emotional intelligence}

E. L. Cowen (1998) suggests five strategies for promoting the amplification of the well-being objectives, in which we encounter objectives from the perspective of developing the competences, such as a traditional perspective, „of risks and protection factors”. These strategies include:

1. Encouraging the development of positive attachment between students and teachers;

2. Helping young people to reach competences particular for the level of development (building friendships, efficient communication);

3. Explaining ways of organizing stress agents;

4. Helping young people to build a feeling of control on their own destiny;

5. Offering new ways of promoting the well-being;

The paradigm of risks and protection factors and the paradigms of developing competences offers valuable points for building efficient educational programs about the development of young people.

These perspectives suggest that the study programs must provide students with the required instruments for improving personal competences in the cognitive, affective and comportment area that will help them to face efficiently stress and bad influences. 
Multiple experts (Scales \& Leffert 1999; Weissberg \& Greenberg 1998) showed that efficient programs must take into consideration the numerous contexts that young people live in. Families, communities, friends and school are frameworks that can help or block the student's success by offering or forbidding their opportunities of emotional competence development that they need for the involvement in constructive activities and for admitting the efforts made.

A series of researchers think that preventive efficient programs must follow multiple objectives, not only one category of comportment with high risks and that damages the health. (Graczyk, Weissberg, Jelias, Greenberg, Zins, 2011).

Such emotional competence promoting programs that possess such attributes need a multifactorial and ample package of strategies of interventions for the accomplishment of the objectives, as well as a unique framework for keeping the cohesion of the intervention. Such unitary framework is Social and Emotional Learning (SEL).

SEL is a process that helps young people to assume the capacity of recognizing and organizing emotions, taking responsible decisions, creating strong relationships with others and becoming healthy and productive individuals.

Social and emotional education (SES) involves adopting a basic group of life, cognitive, affective and comportment competences that promotes the positive growth of young people. Emotional and social education is created in an ideal way in secured and supportive habitation and it can be easily done through a process of modelling, observing, practicing, constructive concreation and counselling. SES gives young people not only the instruments, but also the opportunities of competences used to reach a range of positive, social and healthy results, efficient interpersonal connections, school and career development, responsible citizenship and emotional and physic health.

In order to reach such requirements they need to become competent regarding social and emotional issues. These competences reunite the capacity of understanding, organizing and admitting emotional and social aspects of life in constructive ways, but also to adapt themselves to the complex challenges of growth.

SEL programs are focused in cognitive, behavioral and affective competences that can be classified in five big categories (Grazyck P.A. \& all, 2011):

1. He will be aware of himself and others;

2. Positive and valuable attitudes;

3. Responsible decisions; 
4. Communication skills;

5. Social skills.

Identifying critical competences of SEL represents the first step in helping social and emotional developments of young people. The most important way is the modality in which these competences are implemented because students need to be motivated to learn and to use these competences in real life.

SEL programs use efficient strategies of teaching. These involves modelling the main ability and presenting it in fragments easy to face with, but also offering an ideal habitat to practice this ability through feedback.

SEL programs are focused on active students and use interactive ways of teaching. They use techniques such as group works, discussions, cooperative teaching and play role.

In contrast to traditional teaching approaches such as lectures, interactive strategies help young people to be active during classes not only with teachers, but also with colleagues, as a part of the learning process.

There is a high agreement between the researchers in this area which shows that the efforts of improving emotional and social development to young people are essential for reaching positive growth results. This fact, makes us admit that they are trying a change of paradigm from the traditional concept of school in general, to the actual mission of schools, in particular.

The role of the educational system will not be only to approach the basic aptitudes (writing, reading and math), but also to prepare students for the current situations they are facing now and those that await them in the future.

In the profile literature, we can find efficient ways of improving emotional intelligence at a different number in contrast with the associated areas for professional forming. These includes programs about management forming, communication of development for workers in the bank system, development of empathy for doctors or resolving conflicts for workers in the public area (such as gendarmes, policeman etc.).

To exemplify this, there are the current programs in various areas that are concentrated on the managerial side, which is specific to the economic educational system.

One of the first successful growth relationships aptitude programs was one offered by managers with a medium level from the State of Pennsylvania, being described by Cherniss Cary (2011). The creation consisted in a number of twenty-eight meetings of 90 minutes each. The first phase of the creation was focused on discussions about leaders, the capacity of being a leader, how to be one and also about ways of leading. The next phase, consisted in experience learning exercises, an evaluation of the way of ruling and activities 
about taking and estimate decisions. The evaluation of this program showed that, comparing with a group of control, they become more aware of their own reactions, motivations, feelings, and they became sensitive on the needs of the others and more trustable, as the evaluations made by superiors and subordinates showed.

\section{Conclusions}

Emotional intelligence development allows bringing out intellectual and creativity aptitudes, assuring the success both on a personal and professional level.

The psychical state that practicing motor activity involves makes us find solutions for attracting students in sports classes, but also choose tactics of sports that contributes to the developments of emotional intelligence. The psychologists associate this with some kind of ability that has nothing to do with academic/theoretical intelligence, but with sort of sensibility for practical and people-to-people relations.

\section{Acknowledgement}

All authors have equally contributed to this article.

\section{References}

Barchard, K. A. (2003). Does emotional intelligence assist in the prediction of academic success? Educational and psychological measurement; 63(5): 840-858.

Cherniss, C. (2011). Criterii de evaluare a calităţii programelor şcolare de învăţare socială şi emoțională, în Manual de inteligență emoțională, Reuven Bar-On, Parker, J.D.; 425-429.

Ciarrochi, J., Chan, A., Y., C., Bajgar, J. (2001). A critical evaluation of the emotional intelligence construct. Personality and Individual Differences, March 2000, 28(3): 539-561.

Cowen, E.L. (1998). Changing concepts of prevention in mental health. Journal of Mental Health, 7: 451-461.

Durlak, J.A., Wells, A.M. (1997). Primary prevention mental health programs for children and adolescents: A meta-analytic review. American Journal of Community Psychology; 25, 115-152.

Goleman, D. (2008). Inteligența emoțională. Bucureşti: Ed. Curtea Veche; 130-132.

Graczyk, P.A., Weissberg, J.P., Jelias, M., Greenberg M.T., Zins, J.E. (2011). Criterii de evaluare a calitătii programelor şcolare de invătare socială şi emoțională, în Manual de inteligență emoțională, Reuven Bar-On, Parker, J.D., 2011; 385-387. 
Lane, A., M., Thelwell, R., Devanport, T., J. (2009). Emotional Intelligence and Mood States associated with Optimal Performance. Electronic Journal of Applied Psychology: General Articles, 5(1): 67-73.

Neacşu, I. (2010). Introducere în psibologia educației şi a dę̧voltării. Bucureşti: Ed. Polirom; 221-225.

Roco, M. (2004). Creativitate şi inteligență emoțională. Bucureşti: Ed. Polirom, Bucureşti; 157-158.

Scales, P., \& Leffert, N. (1999). Developmental assets: A synthesis of scientific research on adolescent development. Minneapolis: Search Institute.

Weissberg, R. P., \& Greenberg, M. T. (1998). School and community competenceenhancement and prevention programs. In I. E. Siegel \& K. A. Renninger (Vol. Eds.), Handbook of child psychology. Child psychology in practice. New York: Wiley; 5th Ed, 4: 877-954 